\title{
Herpes Zoster in an Immunocompetent Adult in the Tropic with Vitamin D Deficiency: A Case Report
}

\author{
Evaristus Chinonye Ezema ${ }^{1 *}$, Obioma Onah Ezema ${ }^{2}$ and Emmanuel Joachim Nebuwa ${ }^{3}$ \\ ${ }^{1}$ Department of Anaesthesia, Nnamdi Azikiwe University Teaching Hospital, Nigeria \\ ${ }^{2}$ Intensive Care Unit, Long Island Jewish Hospital, USA \\ ${ }^{3}$ Department of Health Science, Stratford University, USA
}

Open Access

*Corresponding author: Evaristus Chinonye Ezema, Department of Anaesthesia, Nnamdi Azikiwe University Teaching Hospital, Nnewi, Anambra State, Nigeria, Tel: +2348062851003

\begin{abstract}
Human herpes virus infection induces lifelong latent infection that most likely reactivates when the immune system deteriorates. It usually presents with localized, painful vesicular rash in one or contiguous dermatomal distributions. Although, more serious manifestations like aseptic meningitis, acute retinal necrosis, herpes zoster ophthalmicus and Ramsay Hunt syndrome especially in the immunocompromised. We report a case of 2-dermatomal cutaneous herpes zoster in an adult in the tropic with vitamin $\mathrm{D}$ deficiency.
\end{abstract}

\section{Keywords}

Herpes zoster, Immunocompetent, Tropic, Vitamin D

\section{Introduction}

Herpes zoster, well known as shingles is caused by the reactivation of dormant Varicella-Zoster virus which travels from dorsal root ganglion through the sensory nerves down to the dermatomal skin for the manifestation of its characteristic vesicular rashes [1]. There is often a prodrome of headache, malaise, followed by paresthesia, pain, itching and rashes along the dermatomal distribution on the thorax or face [2]. Varicella-Zoster virus is human double stranded DNA virus with manifestation of primary infection as chicken pox or varicella which present clinically as disseminated painful vesicular rashes typically in the childhood [1].

Varicella zoster virus-specific cell mediated immunity is required to halt this viral reactivation and this immunity is strong in the younger ages [3]. This explains the relatively low incidence of shingles in the lower age groups. The cell mediated immunity decreases with aging, and this correlates with increased incidence of herpes zoster in the elderly [4]. Those patients with T-cell deficiency like HIV patients, bone marrow transplant recipients can present with severe forms of herpes zoster [1]. Humoral immunity does not play a role in the protection against the reactivation of herpes zoster virus as antibodies levels are relatively preserved throughout all age groups [3].

The deficiency of vitamin $D$ has been implicated in the pathogenesis and complications of herpes zoster $[5,6]$. However, it is concluded that good exposure of sunlight at the tropics gives adequate vitamin D [7].

Therefore, we present a report of herpes zoster in a middle aged immunocompetent man with vitamin $D$ deficiency at the tropic.

\section{Case Report}

A 42-year-old male banker presented to the anesthesia pain clinic with one day history of gradual onset of severe burning constant pain at the right anterior chest wall below the right nipple. There was no known relieving factor but it was aggravated by mobility. There was associated malaise but no history of insect bite, trauma, fever, nausea or vomiting. There was a history of recent 2-month vacation spent in United States during winter. Patient has taken Tylenol but there was minimal relief. Past medical was remarkable for chicken- 


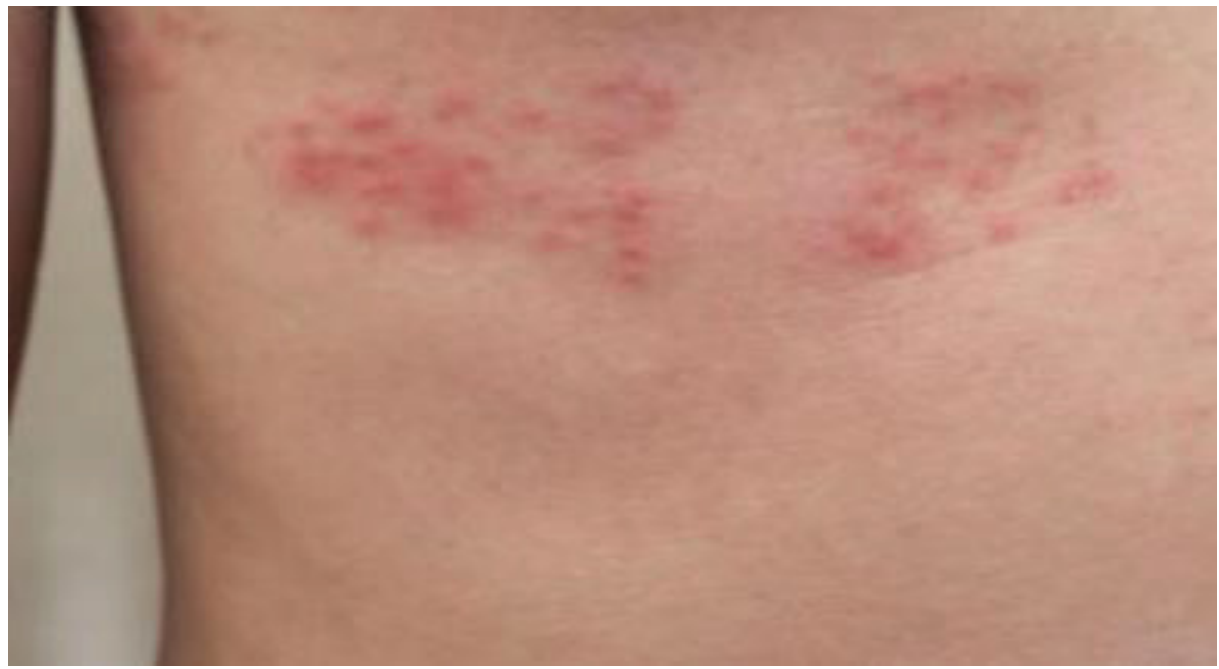

Figure 1: Erythematous rashes at the antero-lateral $T_{5}$ and $T_{6}$ dermatomes.

pox infection during childhood, no varicella vaccination. Family history was not contributory. On a level of 0-10 scale of assessment, patient rated his pain as 10. Physical examination revealed an increased in blood pressure $(142 / 94 \mathrm{mmHg})$ and heart rate $(102 / \mathrm{min})$. His weight was $70 \mathrm{~kg}$ and height $174 \mathrm{~cm}$. There was no peripheral lymphadenopathy, organomegaly or muscle wasting.

There was diffuse tenderness at the right antero-lateral dermatomal level of $T_{5}-T_{6}$, no erythema. A provisional diagnosis of shingle (prodrome pain), to rule out tietze disease was made. Chest X-ray was ordered while blood samples were collected for blood work. Patient was given intravenous $75 \mathrm{mg}$ pethidine and $30 \mathrm{mg}$ ketorolac. He was observed for 8 hours and allowed to go home on oral $75 \mathrm{mg}$ tramadol 6 hourly when his pain scale was 3.

The patient presented with the following day with multiple erythematous vesicular itchy rashes at the same dermatomal level of $T_{5}$ and $T_{6}$ (Figure 1). The results of the blood work and Chest X-ray were normal except cholecalciferol which was $11 \mathrm{ng} / \mathrm{ml}$. Patient was the started on oral $800 \mathrm{mg}$ acyclovir 5 times daily for 1 week, $1000 \mathrm{IU}$ cholecalciferol daily for 1 month, $10 \mathrm{mg}$ loratadine 8 hourly for 5 days and to continue tramadol for extra 5 days. He was subsequently counseled to be exposed to the sunlight at least 30 minutes daily. Follow up visit a week later showed the herpes zoster blisters and discomfort have resolved with no residual neuralgia, although there was still skin dyspigmentation.

\section{Discussion}

The onset of herpes zoster is often heralded by pain and paresthesia within the dermatome(s) by 48 to 72 hours which is followed by areas of erythema. Subsequently, discrete vesicles appear in the distribution of the dermatome that correspond to the infected dorsal root ganglion but does not cross the midline [8]. The diagnosis of herpes zoster is clinically done with clinical appearances and characteristic symptomatology. The most common risk factor for herpes zoster is a decrease in immunity. In such immunocompromised individuals, the herpes zoster lesion may involve multiple dermatomes or wide disseminations in up to $10 \%$ of the individuals but rare in immunocompetent individuals $[8,9]$. Advancing age is another risk factor for herpes zoster especially in the immunocompetent individuals [10-12].

Our patient was a middle aged man, immunocompetent based on history, physical examination findings (no fever, weight loss, lymphadenopathy, organomegaly), laboratory results (normal complete blood count, random plasma glucose, negative HIV screen) and good response to oral acyclovir. He was not on any immunosuppressive medication and did not have any obvious malignancy. However, there was a deficiency of vitamin $D$ noted on the laboratory test. There is increasing evidence of association of vitamin $D$ with reactivation of herpes zoster as shown by Chao, et al. in their study [6]. In another study [5], vitamin D was shown to be closely linked to the clinical courses of herpes zoster, from pathogenesis to complications. There is a possibility of alteration of immunity by the decreased level of vitamin $D$ as a study [12] has shown. The earlier in vivo demonstration of vitamin $D$ deficiency suppressing cell mediated immunity by Yang, et al. [13] might offer exact explanation for the reactivation of herpes zoster in our patient.

Of particular interest is that the patient lives in a tropical country with abundant sunlight. Sunlight is a good source of vitamin $D$ [7]. It might be possible that our patient had reduced exposure to sunlight as the history revealed 2-month vacation in the United States during winter and he was on no vitamin supplement medication. The reduced sun exposure tilts the balance to increased risk for vitamin D deficiency [14]. It is also reported that people with a naturally darker skin require three to five limes longer exposure to sunlight to make adequate amount of vitamin D [15]. 


\section{Conclusion}

Herpes zoster reactivation is rare in immunocompetent individuals but can occur in people with vitamin $D$ deficiency. This case serves as a reminder to the primary care physicians to encourage the patients to maintain their optimum vitamin D level by adequate sunlight exposure and oral vitamin supplementation.

\section{Conflict of Interest}

Nil.

\section{Financial Support}

Nil.

\section{References}

1. Arvin AM (1996) Varicella-zoster virus. Clin Microbiol Rev 9: 361-381.

2. Dayan RR, Peleg R (2017) Herpes zoster-typical and atypical presentations. Postgrad Med 129: 567-571.

3. Arvin A (2005) Aging, immunity, and the varicella-zoster virus. N Engl J Med 352: 2266-2267.

4. Miller AE (1980) Selective decline in cellular immune response to varicella-zoster in the elderly. Neurology 30: 582587.

5. Chao CT, Chiang CK, Huang JW, Hung KY (2015) Vitamin $\mathrm{D}$ is closely linked to the clinical courses of herpes zoster: From pathogenesis to complications. Med Hypotheses 85 : 452-457.
6. Chao CT, Lee ST, Yang SW, Yen CJ, Chiang CK, et al. (2014) Serum vitamin levels are positively associated with varicella zoster immunity in chronic dialysis patients. Sci Rep 4: 7371.

7. Nair R, Maseeh A (2012) Vitamin D: The "sunshine" vitamin. J Pharmacol Pharmacother 3: 118-126.

8. Leung AK, Robson WL, Leong AG (2006) Herpes zoster in childhood. J Pediatr Health Care 20: 300-303.

9. Oladokun RE, Olomukoro CN, Owa AB (2013) Disseminated herpes zoster ophthalmicus in an immunocompetent 8-year old boy. Clin Pract 3: e16.

10. Petrun B, Williams V, Brice S (2015) Disseminated varicella-zoster virus in an immunocompetent adult. Dermatol Online J 21: 13030.

11. Cohen JI (2013) Herpes zoster. N Engl J Med 369: 255263.

12. Aranow $C$ (2011) Vitamin $D$ and the immune system. J Invest Med 59: 881-886.

13. Yang S, Smith C, Prahl JM, Luo X, DeLuca HF (1993) Vitamin $D$ deficiency suppresses cell-mediated immunity in vivo. Arch Biochem Biophys 303: 98-106.

14. Holick MF, Chen TC, Sauter ER (2007) Vitamin D and skin physiology: A D-lightful story. J Bone Miner Res 22: 28-33.

15. Clemens TL, Adams JS, Henderson SL, Holick MF (1982) Increased skin pigment reduces the capacity of skin to synthesis vitamin D3. Lancet 1: 74-76. 